\title{
Organismal Carbohydrate and Lipid Homeostasis
}

\section{Grahame Hardie}

College of Life Sciences, University of Dundee, Dundee DD1 5EH, Scotland, United Kingdom

Correspondence: d.g.hardie@dundee.ac.uk

\section{SUMMARY}

All living organisms maintain a high ATP:ADP ratio to drive energy-requiring processes. They therefore need mechanisms to maintain energy balance at the cellular level. In addition, multicellular eukaryotes have assigned the task of storing energy to specialized cells such as adipocytes, and therefore also need a means of intercellular communication to signal the needs of individual tissues and to maintain overall energy balance at the whole body level. Such signaling allows animals to survive periods of fasting or starvation when food is not available and is mainly achieved by hormonal and nervous communication. Insulin, adipokines, epinephrine, and other agonists thus stimulate pathways that regulate the activities of key enzymes involved in control of metabolism to integrate organismal carbohydrate and lipid metabolism. Overnutrition can dysregulate these pathways and have damaging consequences, causing insulin resistance and type 2 diabetes.

\section{Outline}

1 Introduction

2 Maintaining energy homeostasishormones and adipokines

3 Muscle-acute activation of glycogen breakdown

4 Muscle-acute regulation of glucose uptake and glycogen synthesis

5 Muscle-acute regulation of fatty acid oxidation

6 Muscle-long-term adaptation to exercise

7 Liver-acute regulation of carbohydrate metabolism
8 Liver-long-term regulation of gluconeogenesis via effects on gene expression

9 Liver-regulation of fatty acid, triglyceride, and cholesterol metabolism

10 Adipocytes - regulation of fatty acid metabolism

11 Brown adipocytes - regulation of fatty acid oxidation and heat production

12 Insulin resistance and type 2 diabetesa response to overnutrition?

13 Concluding remarks

References 


\section{INTRODUCTION}

Heterotrophic organisms, including mammals, gain energy from the ingestion and breakdown (catabolism) of reduced carbon compounds, mainly carbohydrates, fats, and proteins. A large proportion of the energy released, rather than appearing simply as heat, is used to convert ADP and inorganic phosphate (Pi) into ATP. The high intracellular ratio of ATP to ADP thus created is analogous to the fully charged state of a rechargeable battery, representing a store of energy that can be used to drive energy-requiring processes, including the anabolic pathways required for cell maintenance and growth. Individual cells must constantly adjust their rates of nutrient uptake and catabolism to balance their rate of ATP consumption, so that they can maintain a constant high ratio of ATP to ADP. The main control mechanism used to achieve this energy homeostasis is AMP-activated protein kinase (AMPK) (see Box 1) (Hardie 2011).

One potential problem for heterotrophic organisms is that there may be prolonged periods when food is not available. They must therefore store molecules like glucose and fatty acids during "times of plenty" to act as reserves for use during periods of fasting or starvation. In multicellular organisms, much of this energy storage function has been devolved to specialized cells. For example, although all mammalian cells (with the possible exception of neurons) can store some glucose in the form of glycogen, large quantities are stored only in muscle and the liver. Similarly, most mammalian cells can store fatty acids in the form of triglyceride droplets in the cytoplasm, but storing large amounts appears to be harmful to many cells (see Insulin Resistance and Type 2 Diabetes section, below). Adipocytes in white adipose tissue have therefore become specialized for triglyceride storage, releasing fatty acids when other tissues need them. In this article, we examine the signaling pathways that coordinate carbohydrate and lipid metabolism between energy-utilizing tissues such as muscle, energy-storing tissues such as adipose tissue, and the liver (an organ that coordinates whole body metabolism).

\section{MAINTAINING ENERGY HOMEOSTASIS- HORMONES AND ADIPOKINES}

The development of multicellular organisms during eukaryotic evolution required the acquisition of systems of hormonal and neuronal signaling that allowed tissues to communicate their needs to each other. In this section, the critical endocrine glands and nerve centers involved in regulation of whole body energy homeostasis, and the hormones and cytokines they produce, are briefly discussed; they are also summarized in Fig. 1. Subsequently, our main focus will be the signaling pathways by which target cells respond to these agents.

\subsection{The Hypothalamus and Pituitary Gland}

The hypothalamus is a small region at the base of the brain that controls critical functions such as body temperature, thirst, hunger, and circadian rhythms. It modulates feeding behavior by producing neuropeptides that promote or repress appetite. The hypothalamus also produces "releasing hormones" (e.g., corticotrophin-releasing hormone $[\mathrm{CRH}]$ and thyrotropin-releasing hormone $[\mathrm{TRH}]$ ) that travel the short distance to the neighboring pituitary gland. Here they trigger release of peptide hormones (e.g., adrenocorticotrophic hormone [ACTH] and thyroid-stimulating hormone $[\mathrm{TSH}]$, released in response to $\mathrm{CRH}$ and TRH, respectively).

\subsection{The Adrenal Gland}

The adrenal gland contains two distinct regions: a central medulla and an outer cortex. The medulla contains modified sympathetic neurons that release epinephrine (a catecholamine also known as adrenaline, formed by oxidation and deamination of the amino acid tyrosine) into the bloodstream. The hypothalamus has projections that connect with sympathetic nerves and can thus trigger epinephrine release. For example, this occurs when blood glucose levels drop, a response that appears to involve activation of AMPK in glucose-sensitive neurons within the hypothalamus (McCrimmon et al. 2008). Release of epinephrine also occurs during exercise and other stressful situations and triggers the "fight or flight response." As well as altering blood flow via effects on the heart and vasculature, epinephrine has many metabolic effects, acting via G-protein-coupled receptors (GPCRs) to increase intracellular cyclic AMP or calcium (Heldin 2012). In muscle, it stimulates glycogen and triglyceride breakdown, providing fuels for accelerated ATP production. In the liver, it promotes release of glucose from glycogen into the bloodstream. In adipose tissue, it mobilizes triglyceride stores, the fatty acids derived either being used as catabolic fuels or, in brown adipose tissue, to generate heat.

The adrenal cortex releases the glucocorticoid cortisol, which (like other steroid hormones) is synthesized from cholesterol. This also occurs in response to starvation or stressful conditions, but in this case is triggered by release of ACTH from the pituitary gland. Acting via nuclear receptors that directly regulate transcription, glucocorticoids promote gluconeogenesis in the liver, protein breakdown in muscle, and triglyceride breakdown in adipose tissue, while reducing insulin-stimulated glucose uptake by muscle. 


\section{BOX 1. THE ENERGY CHARGE HYPOTHESIS AND ENERGY SENSING BY AMP-ACTIVATED} PROTEIN KINASE

Catabolism generates ATP from ADP, whereas anabolism and most other cellular processes, such as the action of motor proteins or membrane pumps, require energy and is usually driven by hydrolysis of ATP to ADP. There is no reason a priori why these opposing processes should automatically remain in balance, and the fact that cellular ATP:ADP ratios are usually rather constant indicates that there are systems inside cells that maintain energy balance. Daniel Atkinson proposed in his energy charge hypothesis that the major signals that regulate cellular energy homeostasis would be ATP, ADP, and AMP (Ramaiah et al. 1964). AMP, like ADP, is a good indicator of energy stress, because its concentration increases as the ADP:ATP ratio increases, owing to displacement of the near-equilibrium reaction catalyzed by adenylate kinase (2ADP $\leftrightarrow$ ATP + AMP). Atkinson's hypothesis was based on findings that two enzymes, glycogen phosphorylase and phosphofructokinase, which catalyze key control points in glycogen breakdown and glycolysis (see main text), are activated by AMPand inhibited by ATP. The discovery of the AMP-activated protein kinase (AMPK) revitalized this concept. Regulation of AMPK by adenine nucleotides is surprisingly complex (Hardie et al. 2011), but provides great flexibility.

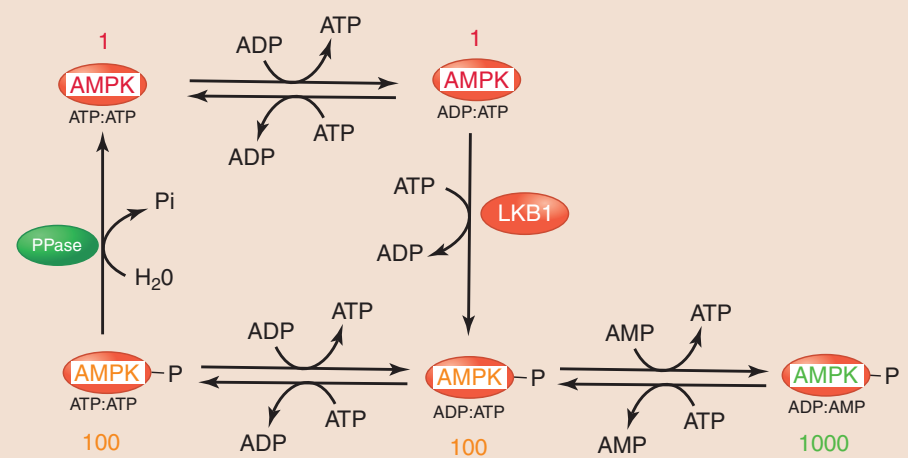

In the diagram above, the numerals below each form refer to its activity relative to the basal state (top left). AMPK is activated $>100$-fold by phosphorylation of a threonine residue (172) within the activation loop of the kinase domain. This is mainly catalyzed by the upstream kinase LKB1, which has a high basal activity. One of the regulatory subunits of AMPK contains two sites that competitively bind the adenine nucleotides AMP, ADP, or ATP. Binding of ADP or AMP (but not ATP) to the first site (top center) causes a conformational change that promotes net phosphorylation of 172 (Oakhill et al. 2011; Xiao et al. 2011), thus causing a switch to the active, phosphorylated form (bottom center; during a mild metabolic stress, the concentration of AMP is much lower than that of ADP, so binding of ADP may be the key event responsible for this change). As stress becomes more severe, binding of AMP (but not ADP or ATP) at the second site causes a further 10-fold allosteric activation (bottom right), the combination of the two effects yielding $>1000$-fold activation overall. As metabolic stress subsides, AMP and ADP concentrations will decrease and they will be replaced in the two regulatory sites by ATP (moving from right to left on the bottom row). This initially causes a loss of the allosteric activation, then a conformational change that promotes dephosphorylation, so that the kinase returns to the basal state (top left). This complex mechanism allows AMPK to be activated in a sensitive but dynamic manner over a wide range of ADP:ATP and AMP:ATP ratios, phosphorylating more and more downstream targets as stress becomes more severe.

\subsection{The Thyroid Gland}

The thyroid gland synthesizes the thyroid hormone thyroxine (also known as T4 because it contains four iodine atoms), via iodination and subsequent combination of two molecules of the amino acid tyrosine present within a large precursor protein called thyroglobulin. Proteolytic breakdown of thyroglobulin releases $\mathrm{T} 4$, but the more potent hormone tri-iodothyronine (T3) is produced by removal of one iodine atom from $\mathrm{T} 4 \mathrm{in}$ other tissues, including the liver. T3 acts, like glucocorticoids, by binding to nuclear receptors that regulate transcription, and has effects on almost all cells. However, a major effect of T3 on whole body energy homeostasis involves inhibition of AMPK in the hypothalamus 
D.G. Hardie

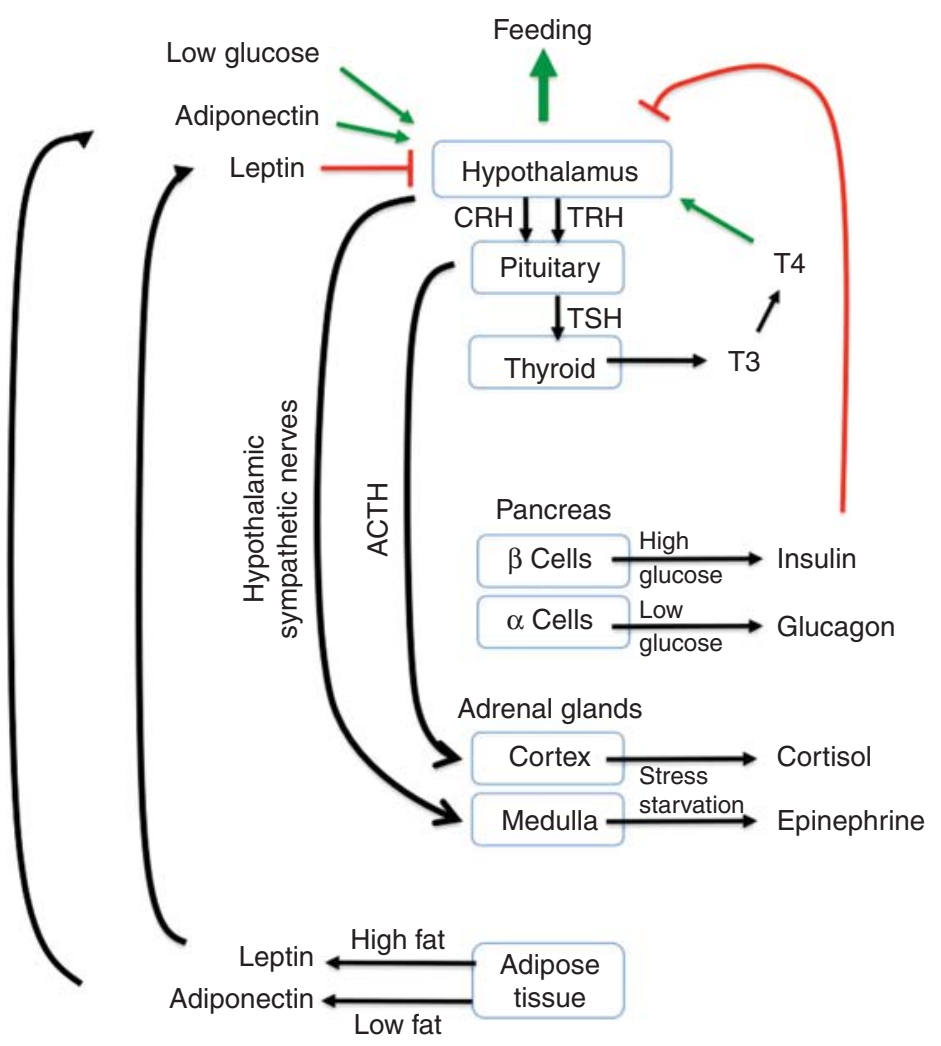

Figure 1. Summary of endocrine systems that regulate energy balance by modulating carbohydrate and lipid metabolism. Neurons in the hypothalamus promote feeding, and the successive release of corticotrophin-releasing hormone (CRH), adenocorticotrophin-releasing hormone (ACTH), and cortisol from the hypothalamus, pituitary, and adrenal cortex, respectively, and release of epinephrine from the adrenal medulla. Hypothalamic neurones are activated by low glucose, the thyroid hormone T3, and adiponectin, while being inhibited by leptin and insulin. The $\alpha$ and $\beta$ cells in the pancreas monitor blood glucose independently, releasing glucagon and insulin, respectively. Insulin and leptin are hormones that represent nutrient surplus, whereas cortisol, epinephrine, and adiponectin are hormones that represent either deprivation of nutrients (e.g., starvation) or demand for energy (e.g., during exercise).

(Lopez et al. 2010). This promotes firing of sympathetic nerves that trigger release of epinephrine from the adrenal medulla. This in turn increases energy expenditure by stimulating white adipose tissue to release fatty acids (which are oxidized in other tissues) and by promoting fatty acid oxidation and heat production in brown adipose tissue.

\subsection{Pancreatic Islets}

The pancreas contains small islands of endocrine tissue called the islets of Langerhans, which are responsible for the secretion of the hormones insulin and glucagon. The $\beta$ cells synthesize insulin, a peptide hormone with two disulfide-linked chains formed by cleavage of a single precursor polypeptide, proinsulin. They release insulin in response to high concentrations of glucose and amino acids that are derived from the gut after feeding, i.e., during "times of plenty." Almost all cells in the body express the insulin receptor, which (like the IGF1 receptor) has two disulfide-linked polypeptide chains, one with a cytoplasmic tyrosine kinase domain. Binding of insulin to this receptor activates phosphoinositide (PI) 3-kinase, which synthesizes phosphatidylinositol 3,4,5-trisphosphate ( $\mathrm{PIP}_{3}$ ) from phosphatidylinositol 4,5-bisphosphate $\left(\mathrm{PIP}_{2}\right)$. The membrane lipid $\mathrm{PIP}_{3}$ is a second messenger that activates the Akt signaling pathway (Hemmings and Restuccia 2012), promoting the cellular uptake of glucose and amino acids, as well as synthesis of fatty acids, and the conversion of these components to forms in which they are stored, i.e., glycogen, proteins, and triglycerides.

The $\alpha$ cells within the islets release another peptide hormone, glucagon, in response to low blood glucose during fasting or starvation. Glucagon binds to $\mathrm{G} \alpha$-linked receptors that increase cyclic AMP levels in the liver (see below), causing a switch from glycolysis to glucose production by gluconeogenesis. It also mobilizes triglyceride stores in adipose tissue, releasing fatty acids into the bloodstream by the process of lipolysis. 


\subsection{Adipose Tissue}

The main function of adipose tissue is to store triglycerides, but it also acts as an endocrine organ, releasing peptide hormones termed adipokines that play key roles in regulating whole body energy balance. One is leptin, a small globular protein whose concentration is elevated in the blood of obese individuals, which suggests that it represents a signal that fat reserves are adequate (Friedman and Halaas 1998). The leptin receptor is a member of the cytokine receptor family, a single-pass membrane protein that lacks intrinsic kinase activity but is coupled via Janus kinases (JAKs) to transcription factors of the STAT family (Harrison 2012). Leptin receptors are expressed in the hypothalamus, and their activation represses synthesis of neuropeptides that promote feelings of hunger, while enhancing synthesis of those that promote satiety, thus reducing appetite. Unfortunately, many obese people appear to have become resistant to the appetite-suppressing effects of leptin.

Another adipokine, adiponectin, is an unusual peptide hormone that has a globular domain linked to a collagenlike sequence that causes it to form disulphide-linked trimers as well as higher-order oligomers (Shetty et al. 2009). Although secreted by adipocytes, adiponectin paradoxically displays high plasma concentrations in lean individuals and low levels in obese individuals, which suggests that it is a signal indicating that fat stores are low. Adiponectin binds to two receptors (AdipoRI and AdipoRII) that are predicted to have seven transmembrane helices, although they differ from GPCRs in that their amino termini are intracellular (Kadowaki and Yamauchi 2005). In general, adiponectin has catabolic and anti-anabolic effects: binding to AdipoRI activates AMPK (via a mechanism that remains unclear), promoting fat oxidation in the liver and muscle, and inhibiting glucose production by the liver. Adiponectin also increases appetite by activating AMPK in the hypothalamus, thus opposing the effects of leptin (Kubota et al. 2007).

\section{MUSCLE-ACUTE ACTIVATION OF GLYCOGEN BREAKDOWN}

The mechanisms by which target cells respond to the hormones and cytokines described in the previous section are discussed below. Skeletal muscle represents the major site of glycogen storage within the body, although because it lacks glucose-6-phosphatase it cannot release glucose back into the bloodstream. Muscle glycogen breakdown is therefore used entirely to meet the energy demands of the muscle itself, and is especially important during periods of intense exercise. The enzyme phosphorylase uses phosphate to split the terminal glycosidic linkages of the outer chains of glycogen, releasing glucose 1-phosphate, which immediately enters glycolysis to generate ATP. 5'-AMP allosterically activates phosphorylase, with ATP antagonizing this effect. Thus, phosphorylase should be activated by an increase in the cellular AMP:ATP ratio, a signal that the energy status of the cell is compromised (see Box 1). One of the key glycolytic enzymes in muscle, phosphofructokinase (PFK1), is also allosterically activated by AMP and inhibited by ATP, so glycolysis should be activated at the same time (Fig. 2).

Phosphorylase occurs not only as the form activated by AMP (called phosphorylase $b$ ), but also as a second form (phosphorylase $a$ ) that is phosphorylated at a serine residue near the amino terminus and active even in the absence of AMP. The enzyme that catalyzes the $b$-to- $a$ transition, phosphorylase kinase, is activated by calcium. When a muscle is stimulated to contract, the neurotransmitter acetylcholine is released at the specialized synapse between the motor nerve and the muscle (the neuromuscular junction). Activation of nicotinic acetylcholine receptors on the muscle cell then causes firing of action potentials that pass down the transverse tubules, triggering opening of voltage-gated calcium channels. This in turn causes opening of calcium-activated calcium channels (ryanodine receptors) on the sarcoplasmic reticulum, leading to a sudden release of calcium from there into the cytoplasm (Ehrlich 2012). This calcium influx triggers muscle contraction (creating a massive demand for ATP), while at the same time activating phosphorylase kinase. Thus, contraction is synchronized with glycogen breakdown, which helps to satisfy the demand for ATP. Phosphorylase kinase was the first of $>500$ mammalian protein kinases to be identified (Fischer and Krebs 1989). It is a large multisubunit complex $\left(\alpha_{4} \beta_{4}\right.$ $\gamma_{4} \delta_{4}$ ), with the $\gamma$ subunit carrying the kinase activity and the $\delta$ subunit being a tightly bound molecule of the calciumbinding protein calmodulin, responsible for activation by calcium. Cyclic-AMP-dependent protein kinase (PKA), which is activated by increases in cyclic AMP when epinephrine acts on muscle, phosphorylates both the $\alpha$ and $\beta$ subunits. This greatly increases the kinase activity of the $\gamma$ subunit, while also making the complex more sensitive to calcium. Note that the PKA $\rightarrow$ phosphorylase kinase pathway was the first protein kinase cascade to be described.

Why does phosphorylase need three tiers of regulation, mediated by AMP, calcium, and cyclic AMP (Fig. 2)? Imagine a mouse suddenly encountering a cat: if the mouse had no phosphorylase kinase (and therefore only had the AMP-activated $b$ form of phosphorylase), it could start to run, but glycogen breakdown would not occur until some ATP had been used up and AMP had increased. The delay involved in this feedback mechanism might be fatal. Indeed, humans with muscle phosphorylase kinase deficiency have been described, and they experience muscle weakness or pain during exercise. If, however, the mouse 


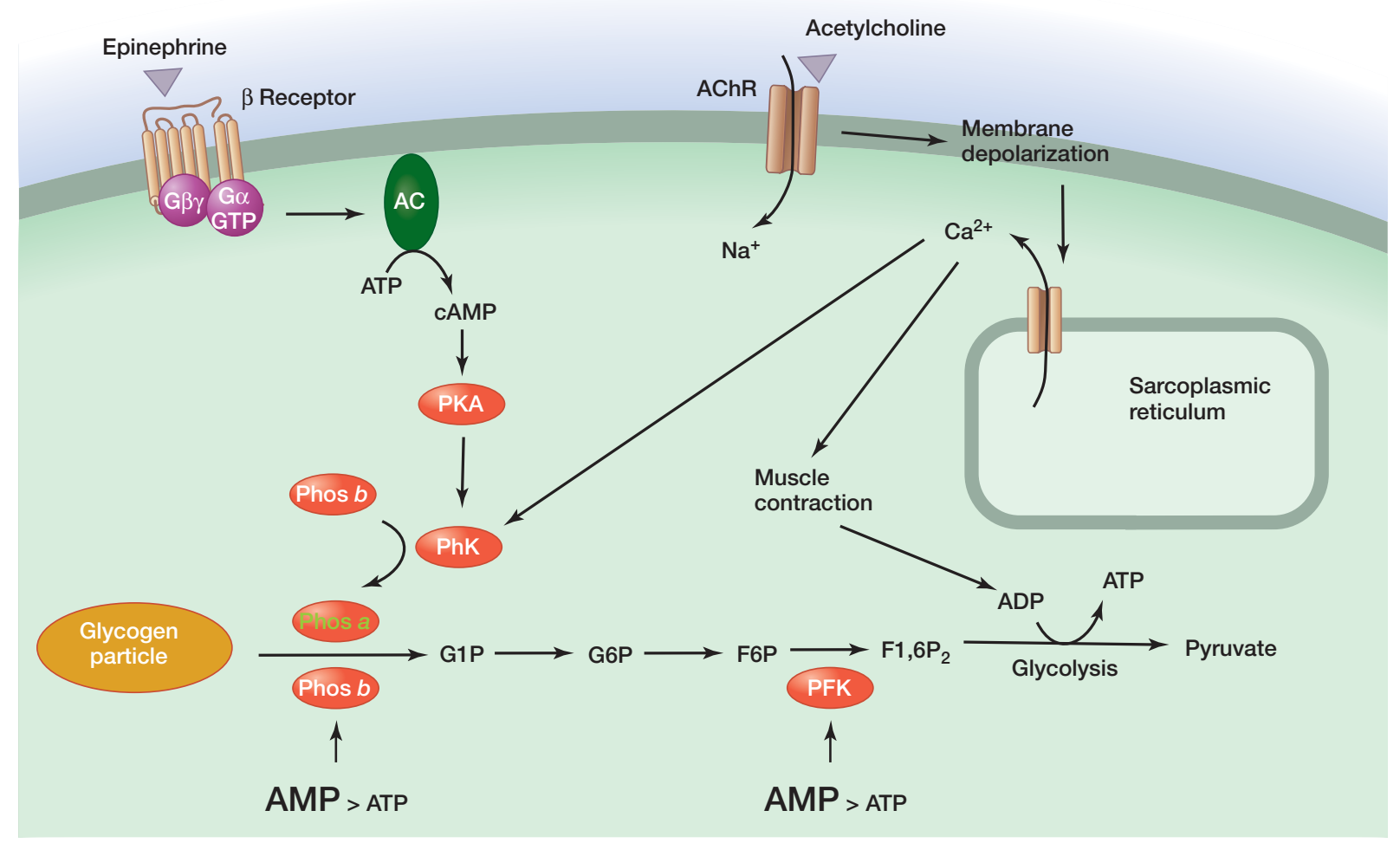

\begin{abstract}
Figure 2. Regulation of glycogen breakdown in skeletal muscle. Muscle contraction increases ADP and AMP and decreases ATP, activating both phosphorylase $b(\operatorname{phos} b)$ and phosphofructokinase (PFK) through allosteric regulation, thus promoting glycogen breakdown and glycolysis to generate ATP. However, contraction (initiated by firing of motor nerves that release acetyl choline) is triggered by release of calcium from channels in the sarcoplasmic reticulum membrane, also activating phosphorylase kinase. The latter phosphorylates phosphorylase and converts it to the $a$ form ( phos $a$ ), which no longer requires AMP for activity. Increases in cyclic AMP levels, triggered by binding of epinephrine to receptors on the plasma membrane, activate cyclic-AMP-dependent protein kinase (PKA). PKA phosphorylates phosphorylase kinase and amplifies its activation by the calcium-dependent mechanism.
\end{abstract}

had phosphorylase kinase, calcium-dependent phosphorylation of phosphorylase would now occur, overriding the allosteric mechanism, and the onset of glycogen breakdown would be synchronized with the onset of muscle contraction. This feed-forward effect of calcium would anticipate the demand for ATP and remove the delay implicit in the allosteric mechanism, thus increasing the chances of escape. Finally, if the mouse is foraging in a place where it might expect trouble, it will be nervous and have high levels of circulating epinephrine. This causes phosphorylation of phosphorylase kinase by PKA, so that when calcium goes up in response to contraction, the conversion of phosphorylase to the more active $a$ form is even more rapid, maximizing the chances of escape.

\section{MUSCLE-ACUTE REGULATION OF GLUCOSE UPTAKE AND GLYCOGEN SYNTHESIS}

Muscle stores of glycogen are finite and cannot maintain rapid ATP production for long periods. Prolonged exercise therefore requires increased uptake of glucose from the bloodstream. In addition, glycogen must be replenished when exercise terminates, and this also requires increased glucose uptake. Muscle expresses the "insulin-sensitive" glucose transporter GLUT4. In the fasted state, it is mainly present in intracellular GLUT4 storage vesicles (GSVs) but insulin released after a meal causes these to fuse with the plasma membrane, increasing the number of transporters at the membrane and hence the rate of glucose uptake (Fig. 3). Fusion of GSVs with the membrane is promoted by small proteins of the Rab family. Under basal conditions, these are maintained in their inactive GDP-bound form by proteins with Rab-GTPase activator protein (Rab-GAP) domains that bind to GSVs. One of these is TBC1D4 (also known as AS160). Binding of insulin to its receptor causes activation of PI 3-kinase (Hemmings and Restuccia 2012), causing the formation of $\mathrm{PIP}_{3}$ and thus activation of Akt. Akt phosphorylates TBC1D4 at multiple sites, causing it to interact with 14-3-3 proteins and dissociate from GSVs. No longer restrained by the Rab-GAP activity of TBC1D4, 


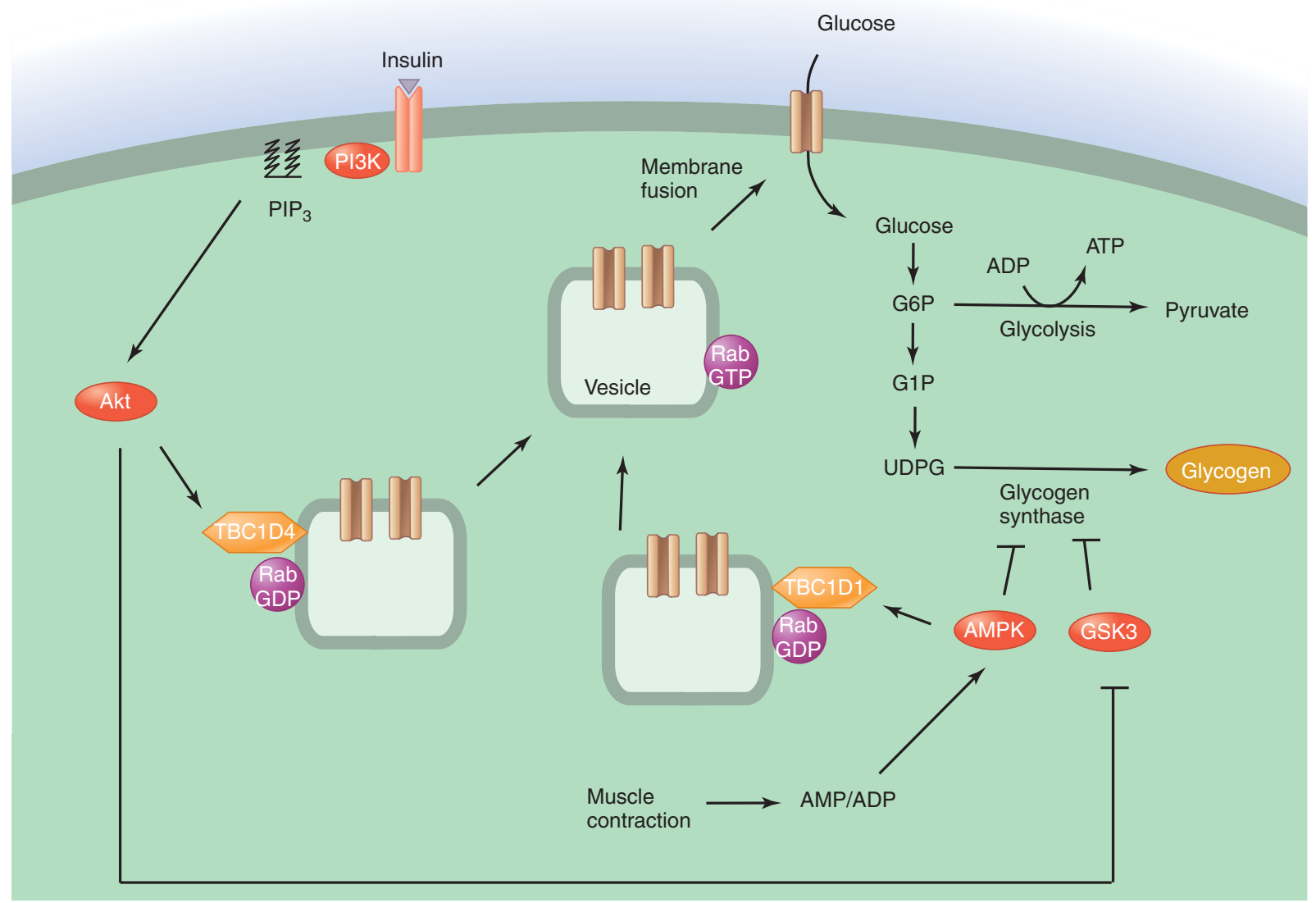

Figure 3. Regulation of muscle glucose uptake and glycogen synthesis by insulin and contraction. In resting muscle in the fed state, insulin binding to its receptor activates the PI-3-kinase $\rightarrow$ Akt pathway. Akt phosphorylates the Rab-GAP protein TBC1D4 (AS160) attached to GLUT4 storage vesicles (GSVs), causing its dissociation and promoting Rab:GTP-mediated fusion of GSVs with the plasma membrane and increased glucose uptake. This causes accumulation of glucose 6-phosphate (G6P), which activates glycogen synthase; the latter is also dephosphorylated and activated following inactivation of GSK3 by Akt. Muscle contraction, by contrast, causes increases in ADP and AMP levels that activate AMPK. AMPK phosphorylates TBC1D1, causing GSVs to fuse with the membrane. In this case, G6P does not accumulate because of the demand for ATP, and AMPK also inactivates glycogen synthase. This drives flux from increased glucose uptake into ATP production rather than glycogen synthesis.

Rab proteins are converted to their active, GTP-bound forms, stimulating fusion of GSVs with the plasma membrane and increasing glucose uptake (Chen et al. 2011).

Glucose uptake triggered by muscle contraction uses a similar mechanism, but is switched on by different signaling pathways. In this case, members of the AMPK family (Box 1) are the key mediators. Exercise consumes ATP and thus increases muscle ADP:ATP and AMP:ATP ratios, activating AMPK. The use of pharmacological activators of AMPK in perfused muscle shows that activating AMPK is sufficient for increased glucose uptake (Merrill et al. 1997), whereas the use of muscle-specific-AMPK-knockout mice shows that AMPK is necessary for a full response, although a small response does remain in its absence (O'Neill et al. 2011). Because a muscle-specific knockout of the upstream kinase for AMPK, LKB1, does appear to abolish the response (Sakamoto et al.
2005), it is possible that another kinase downstream from LKB1 compensates when AMPK is absent. One candidate is the SNF1- and AMPK-related kinase (SNARK, also known as NUAK2) (Koh et al. 2010), although how it is activated during muscle contraction remains unclear.

AMPK stimulates glucose uptake, at least in part, by phosphorylating TBC1D1 (Sakamoto and Holman 2008). As with phosphorylation of its close relative TBC1D4 (also known as AS160) by Akt, this causes association with 143-3 proteins and dissociation from GSVs, promoting their fusion with the plasma membrane. Because the kinase domains of AMPK and SNARK/NUAK2 have closely related sequences, SNARK/NUAK2 might also phosphorylate TBC1D1. Thus, insulin and contraction increase glucose uptake via parallel signaling pathways that converge on the activation of Rab proteins. 
The effects of insulin on muscle are anabolic, and the increased flux through GLUT4 is mainly directed into glycogen synthesis. By contrast, the effects of AMPK are catabolic and the increased flux through GLUT4 is directed into glycolysis and glucose oxidation instead. How are these different metabolic fates determined? Insulin stimulates glucose uptake in resting muscle, when there would not be a large demand for ATP. Glucose 6-phosphate (G6P) would therefore not be metabolized rapidly and would accumulate and activate glycogen synthase, for which G6P is a critical allosteric activator (Bouskila et al. 2010). In addition, glycogen synthase is inactivated by phosphorylation at carboxy-terminal sites by glycogen synthase kinase 3 (GSK3). However, in the presence of insulin, Akt phosphorylates and inactivates GSK3, thus causing a net dephosphorylation and activation of glycogen synthase (McManus et al. 2005) — this represents a second mechanism by which insulin stimulates glycogen synthesis. By contrast, AMPK is activated in contracting muscle, when glycolysis would be activated and G6P would not accumulate. In addition, AMPK itself inactivates glycogen synthase by phosphorylating sites distinct from those phosphorylated by GSK3 (Jorgensen et al. 2004). Thus, whereas insulin activates glycogen synthase, driving flux from increased glucose uptake into glycogen synthesis, AMPK inactivates glycogen synthase, driving flux from increased glucose uptake into glycolysis and glucose oxidation instead (Fig. 3).

\section{MUSCLE-ACUTE REGULATION OF FATTY ACID OXIDATION}

During prolonged, low-intensity exercise, ATP is partly generated by the mitochondrial oxidation of fatty acids. Muscle uptake of plasma fatty acids is catalyzed by transporters such as CD36 that translocate from intracellular vesicles to the membrane. Like GLUT4 translocation, this process is stimulated by AMPK (Bonen et al. 2007), although the mechanism remains unclear in this case. Fatty acids then enter the mitochondrion for oxidation in the form of acylcarnitine esters, which requires a carnitine: palmitoyl transferase, CPT1, on the outer mitochondrial membrane. CPT1 is inhibited by malonyl-CoA, a metabolic intermediate produced in muscle by the ACC2 isoform of acetyl-CoA carboxylase. ACC2 is phosphorylated and inactivated by AMPK, which lowers malonyl-CoA levels and thus stimulates fatty acid oxidation during exercise (Merrill et al. 1997).

\section{MUSCLE-LONG-TERM ADAPTATION TO EXERCISE}

Athletes who train for endurance events have elevated mitochondrial content, allowing them to produce ATP more rapidly by glucose and fatty acid oxidation. Regular endurance exercise increases mitochondrial biogenesis in part through effects of AMPK on the transcriptional coactivator PPAR- $\gamma$ coactivator $-1 \alpha$ (PGC- $1 \alpha)$. PGC- $1 \alpha$ is recruited to DNA by transcription factors that bind to promoters of nuclear genes encoding mitochondrial proteins (Lin et al. 2005). These include the nuclear respiratory factors NRF1 and NRF2, which switch on expression of mitochondrial transcription factor A (TFAM), a mitochondrial matrix protein required for the replication of mitochondrial DNA. PGC- $1 \alpha$ is also recruited to promoters by PPAR- $\alpha$, PPAR- $\delta$, and estrogen-related receptor $\alpha$ (ERR- $\alpha)$, which switch on genes involved in mitochondrial fatty acid oxidation. One of these encodes pyruvate dehydrogenase kinase 4 (PDK4) (Wende et al. 2005). By phosphorylating and inactivating pyruvate dehydrogenase, PDK4 reduces entry of pyruvate into the TCA cycle and thus favors oxidation of fatty acids rather than carbohydrates.

AMPK may stimulate PGC- $1 \alpha$ in part via direct phosphorylation, which is proposed to promote its ability to activate its own transcription, in a positive feedback loop (Jager et al. 2007). However, AMPK activation also causes deacetylation of PGC-1 $\alpha$ (Canto et al. 2010). Up to 13 lysine residues on PGC- $1 \alpha$ are modified by acetylation, a reaction catalyzed by acetyltransferases of the GCN5 and SRC families. This causes PGC- $1 \alpha$ to relocalize within the nucleus, inhibiting its transcriptional activity. The acetyl groups on PGC- $1 \alpha$ are removed by the $\mathrm{NAD}^{+}$-dependent deacetylase SIRT1, which reactivates PGC- $1 \alpha$. AMPK may increase the activity of SIRT1 by increasing the concentration of cytoplasmic $\mathrm{NAD}^{+}$, although the exact mechanism remains uncertain. The "nutraceutical" resveratrol, which is produced by plants in response to fungal infection and is present in small amounts in red wine, has garnered much interest because it extends lifespan in nematode worms and in mice fed a high-fat diet (Baur et al. 2006). It was originally thought to be a direct activator of SIRT1, but it now appears that it may activate SIRT1 indirectly by inhibiting mitochondrial ATP synthesis and thus activating AMPK (Hawley et al. 2010; Um et al. 2010).

\section{LIVER-ACUTE REGULATION OF CARBOHYDRATE METABOLISM}

During starvation, blood glucose levels must be maintained to provide fuel for catabolism, particularly in neurons, which cannot use fatty acids. During short-term fasting, liver glycogen breakdown is the major source of glucose. Epinephrine (acting via Gq-linked, $\alpha 1$ adrenergic receptors coupled to release of inositol 1,4,5-trisphosphate [ $\left.\mathrm{IP}_{3}\right]$ by phospholipase C) increases intracellular calcium levels, whereas glucagon (acting via a $\mathrm{G} \alpha$-linked receptor) 


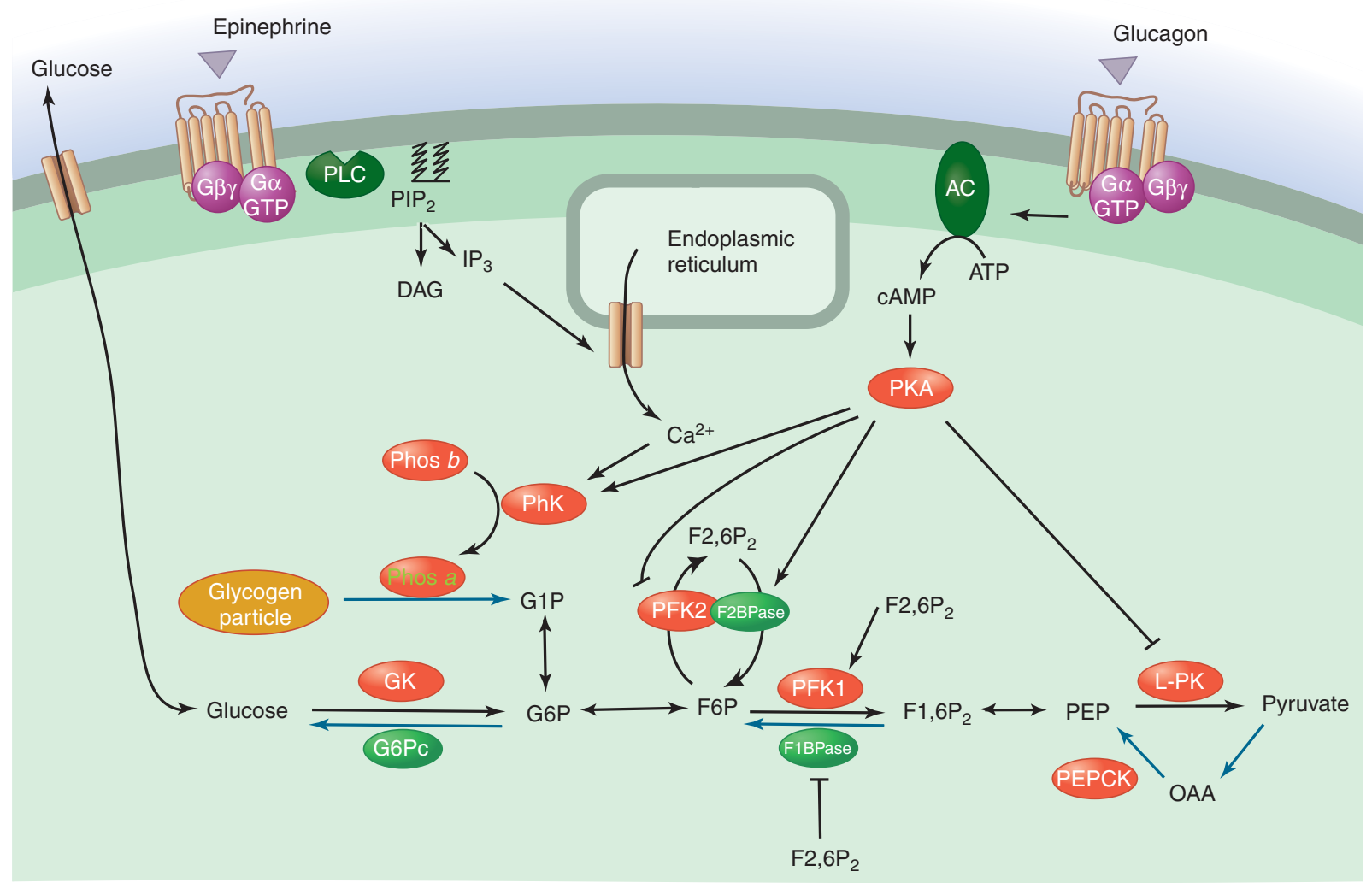

Figure 4. Acute regulation of glycolysis and gluconeogenesis in the liver. Reaction steps unique to glucose release via gluconeogenesis or glycogenolysis are shown in blue. The steps opposing liver pyruvate kinase (L-PK) in gluconeogenesis are not shown in detail. During fasting or starvation, epinephrine and glucagon increase calcium and cyclic AMP (cAMP) levels, activating phosphorylase kinase and cAMP-dependent protein kinase (PKA), which act together to promote glycogen breakdown. During starvation, PKA also phosphorylates L-PK and 6-phosphofructo-2-kinase/fructose 2,6-bisphosphatase (PFK2/F2BPase), inactivating the former, and inhibiting the kinase and activating the phosphatase activity of the latter. This causes a drop in fructose 2,6-bisphosphate levels, which triggers a net switch from glycolysis to gluconeogenesis.

increases the levels of cyclic AMP. Calcium and cyclic AMP then trigger glycogen breakdown in the liver via essentially the same mechanisms as those described above for muscle (Fig. 4). One important difference is that liver cells express glucose-6-phosphatase (and an associated transporter that carries G6P into the ER lumen), which are required for the release of glucose derived from glycogen breakdown into the bloodstream (van Schaftingen and Gerin 2002). The liver also expresses a different isoform of phosphorylase that is not sensitive to AMP. This is consistent with the view that liver glycogen is a store of glucose for use by other tissues, rather than for internal use during periods of energy deficit, as in muscle.

In the liver, glycolysis is most active in the fed state and is an anabolic pathway, because it provides precursors for lipid biosynthesis. The liver is also the major site of gluconeogenesis, the synthesis of glucose from noncarbohydrate precursors, which is essentially a reversal of glycolysis except for three irreversible steps in which different reactions are used (blue arrows in Fig. 4). Gluconeogenesis becomes particularly important as a source of glucose during starvation, particularly for the brain, which cannot use fatty acids. The liver therefore must have mechanisms to trigger a switch from glycolysis to gluconeogenesis during the transition from the fed to the starved state. A key mediator of this switch is a metabolite that has a purely regulatory role, fructose 2-6-bisphosphate, which is synthesized and broken down to fructose 6-phosphate by distinct domains of a single bienzyme polypeptide termed 6-phosphofructo-2-kinase/fructose-2,6-bisphosphatase (PFK2/FBPase) (Fig. 4).

A key step in glycolysis is the conversion of fructose 6-phosphate to fructose 1,6-bisphosphate, catalyzed by 6-phosphofructo-1-kinase (PFK1). PFK1 is allosterically activated by fructose 2, 6-bisphosphate, which also inhibits 
the opposing reaction in gluconeogenesis, catalyzed by fructose-1,6-bisphosphatase. On the transition from the fed to the starved state, glucagon is released, increasing cyclic AMP levels in the liver and activating PKA. PKA phosphorylates the liver isoform of PFK2/FBPase, inhibiting its kinase and activating its phosphatase activity (Rider et al. 2004). The consequent drop in fructose 2,6-bisphosphate levels both reduces PFK1 activation and relieves inhibition of fructose-1,6-bisphosphatase, causing a net switch from glycolysis to gluconeogenesis. In addition, PKA phosphorylates and inactivates the liver isoform of pyruvate kinase (L-PK) (Riou et al. 1978), causing additional inhibition of glycolysis at a later step (Fig. 4).

On returning to the fed state again, blood glucose increases, glucagon levels decrease, and the effects just described are reversed. Some of the increased flux of glucose into the liver caused by the high blood glucose levels also enters the pentose phosphate pathway, generating the intermediate xylulose 5-phosphate. Xylulose 5-phosphate has been found to activate a protein phosphatase that dephosphorylates PFK2/FBPase, thus switching it back to the state that favors fructose 2,6-bisphosphate synthesis (Nishimura et al. 1994).

In muscle, where gluconeogenesis is absent and glycolysis has a purely catabolic role, it would not make sense for hormones that increase cyclic AMP (such as epinephrine) to inhibit glycolysis. Indeed, muscle expresses different isoforms of pyruvate kinase and PFK2/FBPase, which lack the PKA sites.

\section{LIVER-LONG-TERM REGULATION OF GLUCONEOGENESIS VIA EFFECTS ON GENE EXPRESSION}

Another important tier of regulation of glycolysis and gluconeogenesis occurs at the level of transcription. Although expression of most genes involved in these pathways is regulated, research has particularly focused on the genes encoding the catalytic subunit of glucose-6-phosphatase (G6Pc), and phosphoenolpyruvate carboxykinase (PEPCK) (Yabaluri and Bashyam 2010). Although often referred to as "gluconeogenic genes," in fact neither is involved exclusively with that pathway. Thus, glucose-6phosphatase releases into the bloodstream glucose derived from glycogen breakdown as well as gluconeogenesis (Fig. 4), whereas phosphoenolpyruvate produced by PEPCK is used as a precursor for biosynthesis of products other than glucose, including glycerol 3-phosphate used in triglyceride synthesis.

Three important hormonal regulators of transcription of these genes are glucocorticoids and glucagon (which are released during fasting or starvation and increase transcription) and insulin (which is released after carbohydrate feeding and represses transcription). The promoters for these genes contain hormone response units that bind the critical transcription factors and are most well defined in the case of the G6Pc promoter (Fig. 5).

The Glucocorticoid Response Unit. The promoter contains three glucocorticoid response elements (GREs) that

Glucocorticoid response unit

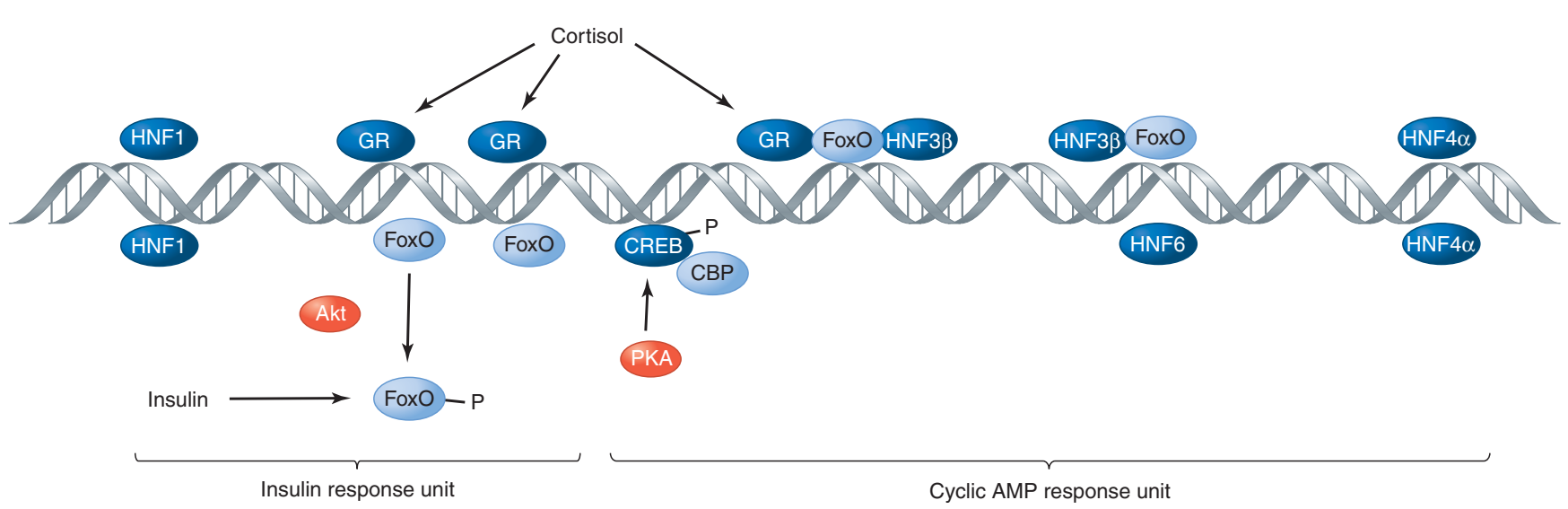

Figure 5. Regulation of the G6Pc promoter, showing the approximate location of elements binding the key transcription factors. Glucocorticoids such as cortisol, in complex with the glucocorticoid receptor (GR), bind to three sites within the glucocorticoid response unit, enhancing transcription. Cyclic AMP-dependent protein kinase (PKA) phosphorylates cyclic AMP response element binding protein (CREB), recruiting CREB-binding protein (CBP), and activating transcription. Finally, Akt phosphorylates FoxO at multiple sites, triggering the binding of 14-3-3 proteins and their nuclear exclusion, thus inhibiting transcription. Not shown are the roles of coactivators other than CBP described in the text, i.e., PGC-1 $\alpha$ and CRTC2. 
bind the glucocorticoid-receptor complex, which activates transcription. However, accessory elements that bind additional transcription factors, including hepatocyte nuclear factors (HNF1 $/ 3 \beta / 4 \alpha / 6)$ and FOXO1, are necessary for a full response.

The Cyclic AMP Response Unit. The promoter contains two cyclic-AMP-response elements (CREs), sequence elements that bind the transcription factor CRE-binding protein (CREB). Glucagon activates PKA, which phosphorylates CREB at 133, promoting binding of the CBP transactivator to activate transcription.

The Insulin Response Unit. The promoter contains two insulin-response elements that bind FoxO1, a transcription factor whose loss leads to decreased expression of both $P E P C K$ and $G 6 P c$ on fasting. FoxO1, along with other members of the forkhead box family, is phosphorylated at multiple conserved sites by Akt, causing its relocalization from the nucleus to the cytoplasm owing to binding of 14-3-3 proteins (Brunet et al. 1999). Insulin also induces expression of COP1, an E3 ubiquitin ligase that promotes FoxO1 degradation by the proteasome (Kato et al. 2008).

Transcription of these genes is also regulated by modulation of various coactivators not shown in Fig. 5, including PGC- $1 \alpha$. The PGC- $1 \alpha$ promoter contains CREs, and in the liver $P G C-1 \alpha$ is a cyclic-AMP-induced gene activated by glucagon. PGC- $1 \alpha$ promotes PEPCK expression in part by interacting with the glucocorticoid receptor. The $\mathrm{NAD}^{+}$dependent deacetylase SIRT1 is also induced in the liver on fasting and, as described above, it deacetylates PGC- $1 \alpha$, increasing transcription of target genes. SIRT1 also deacetylates FOXO1, thus enhancing transcription of G6Pc.

Interestingly, some of these signaling events appear to have arisen during early eukaryotic evolution. In the nematode worm Caenorhabditis elegans, restricting the diet in early life switches development to the long-lived Dauer larval form, and this can be mimicked by mutations in genes encoding orthologues of the insulin/IGF1 receptor (daf-2) or PI-3-kinase (age-1), or overexpression of orthologues of SIRT1 (Sir-2.1) and FoxO1 (Daf-16) (Tissenbaum and Guarente 2001). Thus, dietary restriction extends life span in part by preventing activation of the insulin-like receptor $\rightarrow$ PI-3-kinase $\rightarrow$ Akt pathway, which in turn inhibits the transcription factor FoxO1 (Daf-16) by triggering its phosphorylation and acetylation. Dietary restriction also activates the C. elegans orthologue of AMPK, which activates FoxO1 by phosphorylation at sites different from those targeted by Akt (Greer et al. 2007), and perhaps also by deacetylation. All of these pathways are conserved in mammals, and there is currently intense interest as to whether they regulate mammalian life span in the same manner.

Another transcriptional coactivator that regulates $P E-$ $P C K$ expression is CREB-regulated transcription coactivator
2 (CRTC2, formerly called TORC2), which is recruited to the PEPCK promoter by CREB. CRTC2 is phosphorylated by the protein kinase salt-inducible kinase 1 (SIK1), which triggers binding of 14-3-3 proteins and its relocation from the nucleus to the cytoplasm. However, PKA phosphorylates SIK1, causing its relocalization from the nucleus to the cytoplasm, thus preventing CRTC2 phosphorylation and promoting PEPCK expression. SIK1 is a member of the AMPK-related kinase family and AMPK also phosphorylates CRTC2 at the same site, explaining how AMPK activation switches off PEPCK expression. Interestingly, phosphorylation of the CRTC2 orthologue by AMPK is conserved in C. elegans, and is required for extension of life span by AMPK (Mair et al. 2011).

When would AMPK switch off gluconeogenesis? Adiponectin activates AMPK in the liver via the AdipoRI receptor (see above). This explains how it inhibits hepatic glucose production, and why low adiponectin levels in obese humans correlate with elevated liver glucose production. In addition, AMPK is activated by the antidiabetic drug metformin (see below), which lowers blood glucose levels mainly by repressing gluconeogenesis.

\section{LIVER-REGULATION OF FATTY ACID, TRIGLYCERIDE, AND CHOLESTEROL METABOLISM}

Liver cells carry out both the synthesis and oxidation of fatty acids, and express both isoforms of acetyl-CoA carboxylase (ACC1 and ACC2). By phosphorylating ACC1 and ACC2 at conserved sites to cause their inactivation, AMPK switches off fatty acid synthesis to conserve energy, while switching on fatty acid oxidation to generate more ATP (Hardie 2007). This occurs, for example, when AMPK is activated in the liver by adiponectin. AMPK activation also causes inactivation of glycerol phosphate acyl transferase (GPAT), the first enzyme in the pathway of triglyceride and phospholipid synthesis, although it has not yet been shown to be a direct target for AMPK. Finally, AMPK inhibits cholesterol synthesis by phosphorylation of HMG-CoA reductase (ACC1 and HMG-CoA reductase were, in fact, the first AMPK targets to be identified (Munday et al. 1988; Clarke and Hardie 1990).

In addition to these acute effects, fatty acid and triglyceride synthesis are regulated in the longer term at the level of gene expression. The genes targeted include those whose products are involved directly in these pathways (ACC1, fatty acid synthase, stearoyl-CoA desaturase and GPAT), in the glycolytic pathway that provides the precursors for lipid synthesis (glucokinase, PFK1, aldolase, and L-PK), and in pathways that provide NADPH for the reductive steps in lipid synthesis (glucose-6-phosphate dehydrogenase 
and malic enzyme). These are referred to collectively as lipogenic enzymes, and their expression is up-regulated by carbohydrate feeding, so that excess dietary carbohydrates are converted to triglycerides. The latter are then exported from the liver as very-low-density lipoproteins (VLDL) and carried to adipose tissue for long-term storage.

Carbohydrate feeding causes an increase in blood glucose that also triggers insulin release. Studies with cultured liver cells suggest that increases in both glucose and insulin are necessary for the increased transcription of most lipogenic genes. A transcription factor involved in the effects of insulin is sterol response element-binding protein 1c (SREBP1c). SREBP1a and SREBP1c are derived from the same gene by use of alternate transcription start sites and are closely related to the product of another gene, SREBP2 (Raghow et al. 2008). All three have aminoterminal transcription factor domains (TFDs) linked to carboxy-terminal regulatory domains by two transmembrane $\alpha$ helices that anchor them within the endoplasmic reticulum membrane (Fig. 6). The TFDs are released from the membrane by regulated proteolytic processing; the TFD from SREBP 1a/1c targets mainly lipogenic genes, whereas that from SREBP2 targets genes involved in cholesterol biosynthesis and uptake (including HMG-CoA reductase).
The carboxy-terminal domains of SREBPs bind to ER membrane proteins called SREB cleavage activator protein (SCAP) and Insigs (Insig1/Insig2). When membrane sterol levels are high, they bind to SCAP and Insig1, causing SREBP2 to be retained within the ER. Conversely, when membrane sterol levels are low, SCAP dissociates from Insig2 and the SCAP-SREBP2 complex moves to the Golgi apparatus, where proteinases release the TFD (Yang et al. 2002). Whereas SREBP2 appears to be regulated by sterols mainly at the proteolytic processing step (i.e., sterols inhibit processing), insulin appears to regulate SREBP1c at additional levels, enhancing its transcription and reducing its degradation, and enhancing degradation of Insig2.

Mice lacking SREBP 1c show reduced expression of most lipogenic genes, but their response to carbohydrate feeding is not entirely eliminated. This suggests that other transcription factors also play a role. It has been proposed that the response of lipogenic genes to glucagon and fatty acids (which down-regulate their expression), and high glucose (which induces expression), involves the carbohydrate response element-binding protein (ChREBP) (Uyeda and Repa 2006), a transcription factor with a DNA-binding domain related to that of SREBP-1. ChREBP is phosphorylated at two sites by PKA in response to glucagon, which
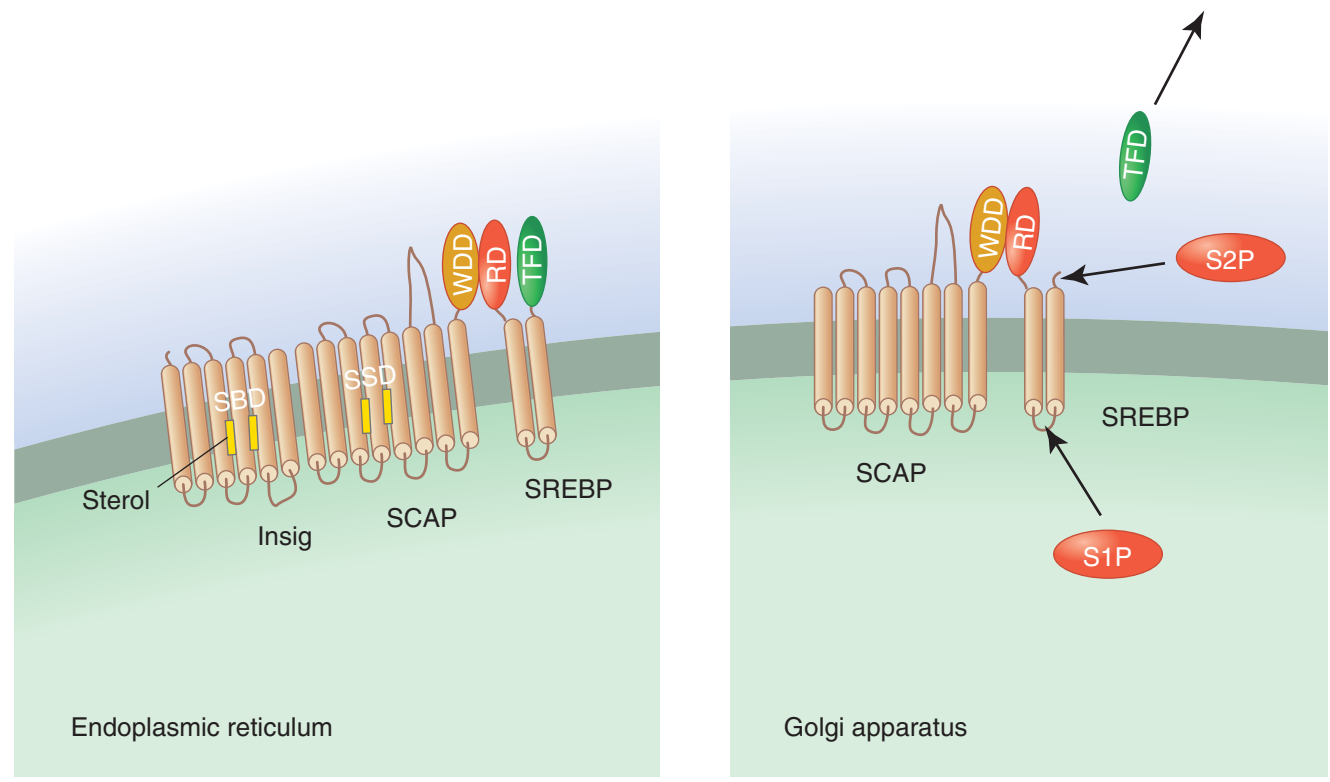

Figure 6. Regulation of processing of SREBPs. The precursor forms of SREBPs bind to the membrane protein SCAP through interactions between their carboxy-terminal regulatory domain (RD) and the WD repeat domain (WDD) of SCAP. The SREBP-SCAP complex is retained in the endoplasmic reticulum by interaction with Insigs. Reduced binding of sterols to the sterol-binding domain (SBD) of Insig1 and the sterol sensor domain (SSD) of SCAP causes their dissociation, and the SCAP-SREBP2 complex then translocates to the Golgi, where the site 1 and site 2 proteases (S1P and S2P) cleave SREBP2, releasing the transcription factor domain (TFD) that translocates to the nucleus. Regulation of SREB1c is similar, except that there appears to be multiple mechanisms that trigger its release from the ER, including insulin-induced degradation of Insig2. 
prevents its nuclear import and inhibits promoter binding. Phosphorylation of a third site by AMPK also inhibits promoter binding and may account for down-regulation of lipogenic genes by adiponectin. It has also been proposed that generation of AMP during conversion of fatty acids to their CoA esters could activate AMPK and explain the effects of fatty acids on lipogenic gene expression. One hypothesis to explain the effect of high glucose is that it is metabolized by the pentose phosphate pathway to xylulose 5-phosphate, which activates the phosphatase that dephosphorylates PFK2/FBPase (see above). This phosphatase is also thought to dephosphorylate the PKA/AMPK sites on ChREBP, promoting its nuclear localization and promoter binding (Kabashima et al. 2003).

\section{ADIPOCYTES - REGULATION OF FATTY ACID METABOLISM}

Although subcutaneous fat provides thermal insulation, the main metabolic function of adipocytes is to store fatty acids as triglycerides, neutral lipids that are very insoluble in water and are deposited in lipid droplets. White adipocytes, unlike other cells, have a single central triglyceride droplet that occupies almost the entire volume of the cell. The phospholipid monolayer that forms its cytoplasmic face is lined with a protein called peripilin1 (Brasaemle 2007). To release fatty acids back into the circulation, the triglycerides in the lipid droplet must be hydrolyzed back to free fatty acids (lipolysis). Three lipases are involved, which remove the first, second, and third fatty acids: (1) adipose tissue triglyceride lipase (ATGL), (2) hormonesensitive lipase (HSL), and (3) monacylglycerol lipase. Lipolysis is greatly enhanced during fasting by glucagon and/or epinephrine, acting via increases in cyclic AMP; insulin opposes this because Akt phosphorylates and activates the cyclic AMP phosphodiesterase PDE3B, thus lowering cyclic AMP levels (Berggreen et al. 2009). HSL is directly phosphorylated and activated by PKA, although the effect on activity is modest (about twofold) compared with the effects on lipolysis (at least 100-fold). Phosphorylation of HSL also triggers its translocation from the cytoplasm to the lipid droplet, thus increasing its accessibility to substrate (Clifford et al. 2000). However, some hormone-stimulated release of fatty acids still occurs even in adipocytes from HSL-deficient mice (Haemmerle et al. 2002). This may be because perilipin 1, which seems to regulate access of lipolytic enzymes to the surface of the lipid droplet, is also phosphorylated by PKA (Clifford et al. 2000). Adipocytes from perilipin 1 knockout mice have a high basal lipolytic rate that is only marginally stimulated by cyclic-AMP-elevating agents (Tansey et al. 2001). The crucial effect of PKA may therefore be to phosphorylate perilipin1, which alters the accessibility of triglycerides within the lipid droplet to both ATGL and HSL.

Activation of AMPK opposes the effects of epinephrine and glucagon on lipolysis, in part because it phosphorylates HSL at sites close to the PKA sites, antagonizing the activation and translocation induced by PKA (Daval et al. 2005). Whether AMPK also antagonizes the effect of phosphorylation of perilipin1 by PKA remains unclear. It might appear paradoxical that AMPK inhibits lipolysis, because fatty acids are an excellent fuel for oxidative catabolism. However, the fatty acids produced by lipolysis are not usually oxidized within the adipocyte, but are released for use elsewhere. If the fatty acids generated by lipolysis are not rapidly removed from adipocytes either by export or by oxidative metabolism, they are recycled into triglycerides, an energy-intensive process in which two molecules of ATP are consumed per fatty acid. Thus, inhibition of lipolysis by AMPK may ensure that the rate of lipolysis does not exceed the rate at which the fatty acids can be removed from the system.

\section{BROWN ADIPOCYTES - REGULATION OF FATTY ACID OXIDATION AND HEAT PRODUCTION}

Brown adipocytes are so called because, unlike white fat cells, they have abundant mitochondria containing cytochromes that produce their characteristic color. Increases in cyclic AMP levels induced by epinephrine trigger lipolysis as in white fat cells, but brown adipocytes differ in that the fatty acids are not released but are oxidized within their own mitochondria. Another unique feature of brown adipocytes is that they express uncoupling protein1 (UCP1), which dissipates the electrochemical gradient produced by pumping of protons across the inner mitochondrial membrane by the respiratory chain. The energy expended in brown fat cells therefore mainly appears in the form of heat, rather than ATP. This heat-generating system is particularly important in neonatal animals (including humans), but also occurs in adult rodents exposed to cold environments. Once thought to be absent in adult humans, improved methodology has shown that brown fat does indeed occur (van Marken Lichtenbelt et al. 2009). These findings have rekindled interest in the idea that regulation of energy expenditure by brown fat might be a way of controlling obesity.

\section{INSULIN RESISTANCE AND TYPE 2 DIABETES - A RESPONSE TO OVERNUTRITION?}

Insulin resistance is a condition in which tissues become resistant to the effects of the hormone, and individuals with 
type 2 diabetes have a high fasting blood glucose level caused primarily by insulin resistance (rather than lack of insulin as in type 1 diabetes). In insulin-resistant individuals, muscle takes up less glucose in response to insulin, and the hormone is also less effective at suppressing glucose production by the liver. Blood glucose therefore remains elevated for longer periods after a carbohydrate meal, a condition known as glucose intolerance. Many individuals who are insulin resistant compensate by secreting more insulin so that, although they may show glucose intolerance, in the fasting state their blood glucose is within the normal range such that they are not classed as diabetic. However, this compensation mechanism may eventually fail, and insulin-resistant individuals often become diabetic.

As the world has become more developed and urbanized, there has been an alarming increase in the prevalence of type 2 diabetes. By 2025 it is predicted that the number with the disorder will increase to $>300$ million (nearly $4 \%$ of the world population). The increase is particularly evident in countries where economic development has been very rapid, like China, where in $2010>90$ million adults were estimated to have diabetes (Yang et al. 2010).

What is the reason for this dramatic increase? Type 2 diabetes is strongly associated with obesity: in one large study, females who were obese (body mass index [BMI] $>30 \mathrm{~kg} / \mathrm{m}^{2}$ ) had a 20 -fold higher risk of developing diabetes compared with those who were lean (BMI $<$ $23 \mathrm{~kg} / \mathrm{m}^{2}$ ) (Hu et al. 2001). This is a serious problem, because over one-quarter of the U.S. population now have a BMI $>30$. Obesity is caused by excessive energy intake (overnutrition) and/or reduced energy expenditure (less physical activity). At the cellular level, insulin resistance can be regarded as a response to excessive storage of nutrients, especially lipids, and it can be reproduced in vitro by incubating cells with high concentrations of glucose or fatty acids. Excessive storage of triglycerides appears to be a particular culprit (Samuel et al. 2010). This is dramatically illustrated by lipodystrophy, a lack of white adipose tissue that can be caused either by rare genetic disorders, or as a side effect of antiviral drugs used to treat AIDS patients (Garg 2004). In both cases, excessive amounts of triglyceride are stored in the liver and muscle instead, and these tissues become profoundly insulin resistant. It appears that large amounts of triglyceride can be stored with relative safety in adipocytes, but that, if stored elsewhere, they become very damaging. Indeed, the tendency to insulin resistance in obese people may be because their adipose tissue stores are already full, leading to increased lipid storage (steatosis) in the liver and muscle.

The current frontline drug used to treat type 2 diabetes is metformin, prescribed to more than 100 million people in 2010. Derived from an ancient herbal remedy, it activates
AMPK, which it does either by inhibiting complex I of the mitochondrial respiratory chain (Owen et al. 2000) or by inhibiting AMP deaminase (Ouyang et al. 2011), both of which increase the cellular AMP:ATP and ADP:ATP ratios (Hawley et al. 2010). By mechanisms already discussed, AMPK activation inhibits synthesis and storage of fat and promotes its oxidation instead, promotes glucose uptake and oxidation by muscle, and inhibits gluconeogenesis in the liver. All of these effects would be beneficial in individuals with insulin resistance and/or type 2 diabetes. There remains some controversy as to whether AMPK activation explains all therapeutic effects of metformin (Foretz et al. 2010). Nevertheless, it is intriguing that a drug used to treat diabetes activates a signaling pathway switched on by exercise. There is much evidence to show that regular exercise protects against development of insulin resistance, and conversely that physical inactivity is a factor contributing to its occurrence. Thus, metformin may at least partly be acting as an exercise mimetic.

There is also much debate about the underlying causes of insulin resistance at the molecular level. Disturbances in lipid metabolites, inflammatory mediators, and adipokines have all been proposed. Whatever the underlying mechanisms, insulin resistance is likely to be a feedback mechanism that has evolved to limit nutrient uptake under conditions when cellular stores of nutrients are already replete. The key to understanding insulin resistance may lie in working out how cells detect when their nutrient stores are full. Although leptin and adiponectin appear to be released from adipocytes when their triglyceride stores are high and low, respectively, we currently know very little at the molecular level about how the level of intracellular stores of lipids (or other nutrients, like glycogen) are monitored.

\section{CONCLUDING REMARKS}

Energy balance in multicellular organisms involves a complex interplay between energy-utilizing tissues such as muscle, energy-storing tissues such as adipose tissue, and organs involved in metabolic coordination such as the liver. These tissues signal to each other via hormones and cytokines that are either secreted by specialized endocrine cells (e.g., the hypothalamus, islets of Langerhans, pituitary, thyroid, and adrenal glands) or by the tissues themselves (e.g., adipokines, released by adipocytes). These hormones either act at receptors that switch on protein kinase signaling cascades triggered by second messengers such as $\mathrm{PIP}_{3}$ (insulin), calcium (epinephrine acting at $\alpha 1$ receptors) or cyclic AMP (glucagon), or bind to nuclear receptors that are transcription factors (cortisol and T3). These signaling cascades interact with other signaling pathways involved in regulating energy balance at the cell-autonomous level 
(e.g., AMPK). The net effect is modulation of carbohydrate and lipid metabolism, both by direct phosphorylation of metabolic enzymes and by effects of gene expression or protein turnover. One important remaining challenge is to understand how cells monitor their levels of energy reserves such as triglyceride, a process likely to be important in understanding disorders such as obesity and type 2 diabetes.

\section{REFERENCES}

* Reference is also in this collection.

Baur JA, Pearson KJ, Price NL, Jamieson HA, Lerin C, Kalra A, Prabhu VV, Allard JS, Lopez-Lluch G, Lewis K, et al. 2006. Resveratrol improves health and survival of mice on a high-calorie diet. Nature 444: $337-342$.

Berggreen C, Gormand A, Omar B, Degerman E, Goransson O. 2009. Protein kinase B activity is required for the effects of insulin on lipid metabolism in adipocytes. Am J Physiol Endocrinol Metab 296: E635-E646.

Bonen A, Han XX, Habets DD, Febbraio M, Glatz JF, Luiken JJ. 2007. A null mutation in skeletal muscle FAT/CD36 reveals its essential role in insulin- and AICAR-stimulated fatty acid metabolism. Am J Physiol Endocrinol Metab 292: E1740-E1749.

Bouskila M, Hunter RW, Ibrahim AF, Delattre L, Peggie M, van Diepen JA, Voshol PJ, Jensen J, Sakamoto K. 2010. Allosteric regulation of glycogen synthase controls glycogen synthesis in muscle. Cell Metab 12: $456-466$.

Brasaemle DL. 2007. Thematic review series: Adipocyte biology. The perilipin family of structural lipid droplet proteins: Stabilization of lipid droplets and control of lipolysis. J Lipid Res 48: 2547-2559.

Brunet A, Bonni A, Zigmond MJ, Lin MZ, Juo P, Hu LS, Anderson MJ, Arden KC, Blenis J, Greenberg ME. 1999. Akt promotes cell survival by phosphorylating and inhibiting a Forkhead transcription factor. Cell 96: 857-868.

Canto C, Jiang LQ, Deshmukh AS, Mataki C, Coste A, Lagouge M, Zierath JR, Auwerx J. 2010. Interdependence of AMPK and SIRT1 for metabolic adaptation to fasting and exercise in skeletal muscle. Cell Metab 11: $213-219$.

Chen S, Wasserman DH, MacKintosh C, Sakamoto K. 2011. Mice with AS160/TBC1D4-Thr649Ala knockin mutation are glucose intolerant with reduced insulin sensitivity and altered GLUT4 trafficking. Cell Metab 13: 68-79.

Clarke PR, Hardie DG. 1990. Regulation of HMG-CoA reductase: Identification of the site phosphorylated by the AMP-activated protein kinase in vitro and in intact rat liver. EMBO J 9: 2439-2446.

Clifford GM, Londos C, Kraemer FB, Vernon RG, Yeaman SJ. 2000. Translocation of hormone-sensitive lipase and perilipin upon lipolytic stimulation of rat adipocytes. J Biol Chem 275: 5011-5015.

Daval M, Diot-Dupuy F, Bazin R, Hainault I, Viollet B, Vaulont S, Hajduch E, Ferre P, Foufelle F. 2005. Anti-lipolytic action of AMP-activated protein kinase in rodent adipocytes. J Biol Chem 280: 2525025257.

* Ehrlich B. 2012. Signaling in muscle. Cold Spring Harb Perspect Biol doi: $10.1101 /$ cshperspect.a006023.

Fischer EH, Krebs EG. 1989. Commentary on "The phosphorylase b to a converting enzyme of rabbit skeletal muscle". Biochim Biophys Acta 1000: $297-301$.

Foretz M, Hebrard S, Leclerc J, Zarrinpashneh E, Soty M, Mithieux G, Sakamoto K, Andreelli F, Viollet B. 2010. Metformin inhibits hepatic gluconeogenesis in mice independently of the LKB1/AMPK pathway via a decrease in hepatic energy state. J Clin Invest 120: 2355-2369.

Friedman JM, Halaas JL. 1998. Leptin and the regulation of body weight in mammals. Nature 395: 763-770.
Garg A. 2004. Acquired and inherited lipodystrophies. New Engl J Med 350: $1220-1234$.

Greer EL, Dowlatshahi D, Banko MR, Villen J, Hoang K, Blanchard D, Gygi SP, Brunet A. 2007. An AMPK-FOXO pathway mediates longevity induced by a novel method of dietary restriction in C. elegans. Curr Biol 17: $1646-1656$.

Haemmerle G, Zimmermann R, Hayn M, Theussl C, Waeg G, Wagner E, Sattler W, Magin TM, Wagner EF, Zechner R. 2002. Hormonesensitive lipase deficiency in mice causes diglyceride accumulation in adipose tissue, muscle, and testis. J Biol Chem 277: 4806-4815.

Hardie DG. 2007. AMP-activated/SNF1 protein kinases: Conserved guardians of cellular energy. Nat Rev Mol Cell Biol 8: 774-785.

Hardie DG. 2011. AMP-activated protein kinase-An energy sensor that regulates all aspects of cell function. Genes Dev 25: 1895-1908.

Hardie DG, Carling D, Gamblin SJ. 2011. AMP-activated protein kinase: Also regulated by ADP? Trends Biochem Sci 36: 470-477.

* Harrison D. 2012. JAK-STAT signalling. Cold Spring Harb Perspect Biol doi: $10.1101 /$ cshperspect.a011205.

Hawley SA, Ross FA, Chevtzoff C, Green KA, Evans A, Fogarty S, Towler MC, Brown LJ, Ogunbayo OA, Evans AM, et al. 2010. Use of cells expressing $\gamma$ subunit variants to identify diverse mechanisms of AMPK activation. Cell Metab 11: 554-565.

* Heldin CH. 2012. Signals and receptors. Cold Spring Harb Perspect Biol doi: $10.1101 /$ cshperspect.a005900.

* Hemmings BA, Restuccia DF. 2012. The PI3K/Akt pathway. Cold Spring Harb Perspect Biol doi: 10.1101/cshperspect.a011189.

Hu FB, Manson JE, Stampfer MJ, Colditz G, Liu S, Solomon CG, Willett WC. 2001. Diet, lifestyle, and the risk of type 2 diabetes mellitus in women. New Engl J Med 345: 790-797.

Jager S, Handschin C, St-Pierre J, Spiegelman BM. 2007. AMP-activated protein kinase (AMPK) action in skeletal muscle via direct phosphorylation of PGC-1 $\alpha$. Proc Natl Acad Sci 104: 12017-12022.

Jorgensen SB, Nielsen JN, Birk JB, Olsen GS, Viollet B, Andreelli F, Schjerling P, Vaulont S, Hardie DG, Hansen BF, et al. 2004. The $\alpha 2$ 5'AMP-activated protein kinase is a site 2 glycogen synthase kinase in skeletal muscle and is responsive to glucose loading. Diabetes 53: 3074-3081.

Kabashima T, Kawaguchi T, Wadzinski BE, Uyeda K. 2003. Xylulose 5phosphate mediates glucose-induced lipogenesis by xylulose 5-phosphate-activated protein phosphatase in rat liver. Proc Natl Acad Sci 100: $5107-5112$.

Kadowaki T, Yamauchi T. 2005. Adiponectin and adiponectin receptors. Endocr Rev 26: 439-451.

Kato S, Ding J, Pisck E, Jhala US, Du K. 2008. COP1 functions as a FoxO1 ubiquitin E3 ligase to regulate FoxO1-mediated gene expression. J Biol Chem 283: 35464-35473.

Koh HJ, Toyoda T, Fujii N, Jung MM, Rathod A, Middelbeek RJ, Lessard SJ, Treebak JT, Tsuchihara K, Esumi H, et al. 2010. Sucrose nonfermenting AMPK-related kinase (SNARK) mediates contraction-stimulated glucose transport in mouse skeletal muscle. Proc Natl Acad Sci 107: 15541-15546.

Kubota N, Yano W, Kubota T, Yamauchi T, Itoh S, Kumagai H, Kozono H, Takamoto I, Okamoto S, Shiuchi T, et al. 2007. Adiponectin stimulates AMP-activated protein kinase in the hypothalamus and increases food intake. Cell Metab 6: 55-68.

Lin J, Handschin C, Spiegelman BM. 2005. Metabolic control through the PGC-1 family of transcription coactivators. Cell Metab 1: 361-370.

Lopez M, Varela L, Vazquez MJ, Rodriguez-Cuenca S, Gonzalez CR, Velagapudi VR, Morgan DA, Schoenmakers E, Agassandian K, Lage R, et al. 2010. Hypothalamic AMPK and fatty acid metabolism mediate thyroid regulation of energy balance. Nat Med 16: 1001-1008.

Mair W, Morantte I, Rodrigues AP, Manning G, Montminy M, Shaw RJ, Dillin A. 2011. Lifespan extension induced by AMPK and calcineurin is mediated by CRTC- 1 and CREB. Nature 470: 404-408.

McCrimmon RJ, Shaw M, Fan X, Cheng H, Ding Y, Vella MC, Zhou L, McNay EC, Sherwin RS. 2008. Key role for AMP-activated protein 
kinase in the ventromedial hypothalamus in regulating counterregulatory hormone responses to acute hypoglycemia. Diabetes 57: 444450.

McManus EJ, Sakamoto K, Armit LJ, Ronaldson L, Shpiro N, Marquez R, Alessi DR. 2005. Role that phosphorylation of GSK3 plays in insulin and Wnt signalling defined by knockin analysis. EMBO J 24: 15711583.

Merrill GM, Kurth E, Hardie DG, Winder WW. 1997. AICAR decreases malonyl-CoA and increases fatty acid oxidation in skeletal muscle of the rat. Am J Physiol 273: E1107-E1112.

Munday MR, Campbell DG, Carling D, Hardie DG. 1988. Identification by amino acid sequencing of three major regulatory phosphorylation sites on rat acetyl-CoA carboxylase. Eur J Biochem 175: 331-338.

Nishimura M, Fedorov S, Uyeda K. 1994. Glucose-stimulated synthesis of fructose 2,6-bisphosphate in rat liver. Dephosphorylation of fructose 6-phosphate, 2-kinase:fructose 2,6-bisphosphatase and activation by a sugar phosphate. J Biol Chem 269: 26100-26106.

O'Neill HM, Maarbjerg SJ, Crane JD, Jeppesen J, Jorgensen SB, Schertzer JD, Shyroka O, Kiens B, van Denderen BJ, Tarnopolsky MA, et al. 2011. AMP-activated protein kinase (AMPK) $\beta 1 \beta 2$ muscle null mice reveal an essential role for AMPK in maintaining mitochondrial content and glucose uptake during exercise. Proc Natl Acad Sci 108: 16092-16097.

Oakhill JS, Steel R, Chen ZP, Scott JW, Ling N, Tam S, Kemp BE. 2011. AMPK is a direct adenylate charge-regulated protein kinase. Science 332: $1433-1435$.

Ouyang J, Parakhia RA, Ochs RS. 2011. Metformin activates AMP kinase through inhibition of AMP deaminase. J Biol Chem 286: 1-11.

Owen MR, Doran E, Halestrap AP. 2000. Evidence that metformin exerts its anti-diabetic effects through inhibition of complex 1 of the mitochondrial respiratory chain. Biochem J 348: 607-614.

Raghow R, Yellaturu C, Deng X, Park EA, Elam MB. 2008. SREBPs: The crossroads of physiological and pathological lipid homeostasis. Trends Endocrinol Metab 19: 65-73.

Ramaiah A, Hathaway JA, Atkinson DE. 1964. Adenylate as a metabolic regulator. Effect on yeast phosphofructokinase kinetics. J Biol Chem 239: 3619-3622.

Rider MH, Bertrand L, Vertommen D, Michels PA, Rousseau GG, Hue L. 2004. 6-phosphofructo-2-kinase/fructose-2,6-bisphosphatase: Headto-head with a bifunctional enzyme that controls glycolysis. Biochem $J$ 381: $561-579$.

Riou JP, Claus TH, Pilkis SJ. 1978. Stimulation of glucagon of in vivo phosphorylation of rat hepatic pyruvate kinase. J Biol Chem 253: 656-659.

Sakamoto K, Holman GD. 2008. Emerging role for AS160/TBC1D4 and TBC1D1 in the regulation of GLUT4 traffic. Am J Physiol Endocrinol Metab 295: E29-E37.
Sakamoto K, McCarthy A, Smith D, Green KA, Hardie DG, Ashworth A, Alessi DR. 2005. Deficiency of LKB1 in skeletal muscle prevents AMPK activation and glucose uptake during contraction. EMBO J 24: 18101820.

Samuel VT, Petersen KF, Shulman GI. 2010. Lipid-induced insulin resistance: Unravelling the mechanism. Lancet 375: 2267-2277.

Shetty S, Kusminski CM, Scherer PE. 2009. Adiponectin in health and disease: Evaluation of adiponectin-targeted drug development strategies. Trends Pharmacol Sci 30: 234-239.

Tansey JT, Sztalryd C, Gruia-Gray J, Roush DL, Zee JV, Gavrilova O, Reitman ML, Deng CX, Li C, Kimmel AR, et al. 2001. Perilipin ablation results in a lean mouse with aberrant adipocyte lipolysis, enhanced leptin production, and resistance to diet-induced obesity. Proc Natl Acad Sci 98: 6494-6499.

Tissenbaum HA, Guarente L. 2001. Increased dosage of a sir-2 gene extends lifespan in Caenorhabditis elegans. Nature 410: 227-230.

Um JH, Park SJ, Kang H, Yang S, Foretz M, McBurney MW, Kim MK, Viollet B, Chung JH. 2010. AMP-activated protein kinase-deficient mice are resistant to the metabolic effects of resveratrol. Diabetes 59: $554-563$.

Uyeda K, Repa JJ. 2006. Carbohydrate response element binding protein, ChREBP, a transcription factor coupling hepatic glucose utilization and lipid synthesis. Cell Metab 4: 107-110.

van Marken Lichtenbelt WD, Vanhommerig JW, Smulders NM, Drossaerts JM, Kemerink GJ, Bouvy ND, Schrauwen P, Teule GJ. 2009. Cold-activated brown adipose tissue in healthy men. New Engl J Med 360: 1500-1508.

van Schaftingen E, Gerin I. 2002. The glucose-6-phosphatase system. Biochem J 362: 513-532.

Wende AR, Huss JM, Schaeffer PJ, Giguere V, Kelly DP. 2005. PGC-1 $\alpha$ coactivates PDK4 gene expression via the orphan nuclear receptor ERR $\alpha$ : A mechanism for transcriptional control of muscle glucose metabolism. Mol Cell Biol 25: 10684-10694.

Xiao B, Sanders MJ, Underwood E, Heath R, Mayer FV, Carmena D, Jing C, Walker PA, Eccleston JF, Haire LF, et al. 2011. Structure of mammalian AMPK and its regulation by ADP. Nature 472: 230-233.

Yabaluri N, Bashyam MD. 2010. Hormonal regulation of gluconeogenic gene transcription in the liver. J Biosci 35: 473-484.

Yang T, Espenshade PJ, Wright ME, Yabe D, Gong Y, Aebersold R, Goldstein JL, Brown MS. 2002. Crucial step in cholesterol homeostasis: Sterols promote binding of SCAP to INSIG-1, a membrane protein that facilitates retention of SREBPs in ER. Cell 110: 489-500.

Yang W, Lu J, Weng J, Jia W, Ji L, Xiao J, Shan Z, Liu J, Tian H, Ji Q, et al. 2010. Prevalence of diabetes among men and women in China. New Engl J Med 362: 1090-1101. 


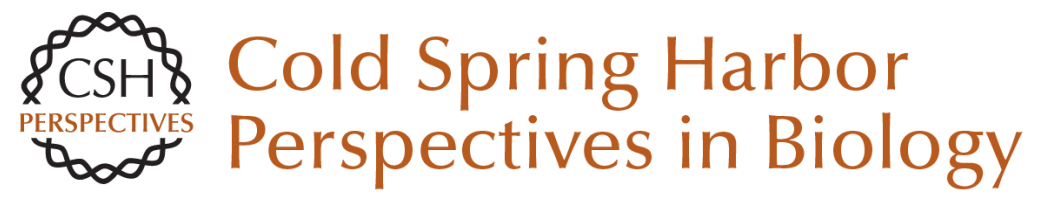

\section{Organismal Carbohydrate and Lipid Homeostasis}

D. Grahame Hardie

Cold Spring Harb Perspect Biol 2012; doi: 10.1101/cshperspect.a006031

Subject Collection Signal Transduction

Cell Signaling and Stress Responses Gökhan S. Hotamisligil and Roger J. Davis

Protein Regulation in Signal Transduction Michael J. Lee and Michael B. Yaffe

Synaptic Signaling in Learning and Memory Mary B. Kennedy

Vertebrate Reproduction Sally Kornbluth and Rafael Fissore

Signaling in Lymphocyte Activation Doreen Cantrell

Signaling in Muscle Contraction Ivana Y. Kuo and Barbara E. Ehrlich

Toll-Like Receptor Signaling Kian-Huat Lim and Louis M. Staudt

Signaling Pathways that Regulate Cell Division Nicholas Rhind and Paul Russell
Second Messengers

Alexandra C. Newton, Martin D. Bootman and John D. Scott

Signals and Receptors Carl-Henrik Heldin, Benson Lu, Ron Evans, et al.

Cell Death Signaling Douglas R. Green and Fabien Llambi

Signaling Networks that Regulate Cell Migration Peter Devreotes and Alan Rick Horwitz

Signaling Networks: Information Flow, Computation, and Decision Making Evren U. Azeloglu and Ravi lyengar

Signal Transduction: From the Atomic Age to the Post-Genomic Era Jeremy Thorner, Tony Hunter, Lewis C. Cantley, et al.

Signaling by the TGF $\beta$ Superfamily Jeffrey L. Wrana

Subversion of Cell Signaling by Pathogens Neal M. Alto and Kim Orth

For additional articles in this collection, see http://cshperspectives.cshlp.org/cgi/collection/

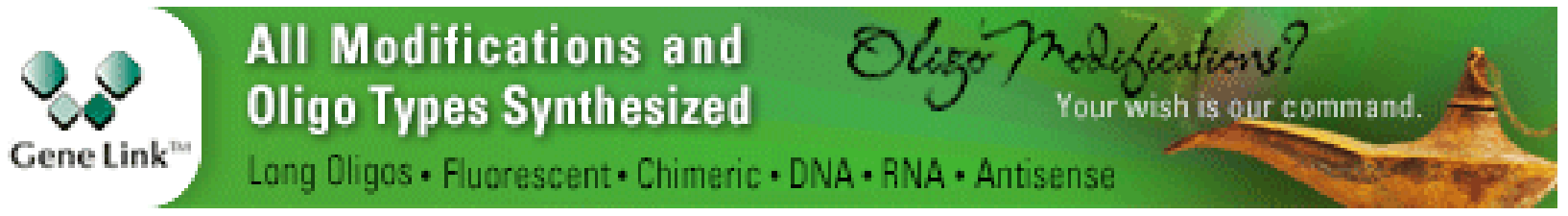

Copyright @ 2012 Cold Spring Harbor Laboratory Press; all rights reserved 